\title{
Comparative Effects of MMT Clay Modified with Two Different Cationic Surfactants on the Thermal and Rheological Properties of Polypropylene Nanocomposites
}

\author{
Meshal Al-Samhan, Jacob Samuel, Fatema Al-Attar, and Gils Abraham \\ Polymeric Product Enhancement \& Customization Program, Kuwait Institute for Scientific Research, P.O. Box 24885, \\ 13109 Safat, Kuwait \\ Correspondence should be addressed to Meshal Al-Samhan; msamhan@kisr.edu.kw
}

Received 15 February 2017; Revised 18 April 2017; Accepted 27 April 2017; Published 31 May 2017

Academic Editor: Xin Ji

Copyright (C) 2017 Meshal Al-Samhan et al. This is an open access article distributed under the Creative Commons Attribution License, which permits unrestricted use, distribution, and reproduction in any medium, provided the original work is properly cited.

Polypropylene montmorillonite (MMT) nanocomposites were prepared by melt blending using two different organoclays modified with imidazolium and alkylammonium surfactants. The imidazolium and ammonium modified organoclays were characterized by the FTIR and SEM analysis. The effect of organic clay (MMT) on the physical properties of polypropylene was evaluated, thermal and rheological properties with different filler weight percentage. Differential scanning calorimetric results showed that imidazolium modified clay (IMMT) exhibits low melting temperature compared to the ammonium modified clay (AMMT). The crystallinity analysis showed that crystallization improved in all nanocomposites irrespective of surface modification; the thermogravimetric analysis showed that the imidazolium modified polymer composites are more thermally stable than conventional ammonium modified composites. The Transmission Electron Microscopy (TEM) analyses indicated that the PPIMMT composites displayed exfoliated morphologies compared with the intercalated structure in PP-AMMT, and the rheological analysis at $180^{\circ} \mathrm{C}$ showed an enhancement in the viscoelastic properties as the clay concentration increases. The melt viscosity, crossover modulus, and relaxation times were comparable for both the surface modified composites with two different cations. The imidazolium based surfactant was found to be an effective organic modification for MMT to prepare thermally stable PP/MMT nanocomposites.

\section{Introduction}

Polymer nanocomposites are ideal reinforced materials for practical applications due to their desired properties and features over the virgin polymeric materials $[1,2]$. These materials show enhanced thermomechanical properties, barrier properties, resistance to chemicals, and fire retardancy with small amounts of a nanofiller [3, 4]. For these nanocomposite systems, the primarily new properties typically originate from the change in the polymer nature by strong interaction with the surrounded filler. In such cases polymers are adsorbed on filler surfaces and strongly depend on the effective surface area of the fillers. Thus, effective dispersions of nanofillers would result in a true nanocomposite at a rather low filler loading, close to the percolation threshold of these high aspect ratio fillers. Utilizing the advantages of nanoscale dimension of these nanofillers, a very small quantity of fillers can be used to improve the physical properties of the polymer as compared to other micro- or macrosized fillers [5]. Moreover, in the absence of true dispersion, the resulting composite is categorized as conventional composite despite the incorporation of the nanometer size inorganic fillers. It has long been recognized that polymers can successfully disperse clay particles when the clay particles are suitably modified; this research field has recently gained considerable thrust, as the report of a nylon-6/montmorillonite (MMT) material by the in situ intercalative polymerization process has been reported $[3,4]$. Since then, the clay nanocomposite research has gained high momentum with emerging applications. In order to achieve a considerable enhancement in the thermal and 
mechanical properties obtaining a nanoscale dispersion of silicate layers as the exfoliated composite structure is required, in which the polymer chains are inserted into the gallery space of the clay layers $[6,7]$. To achieve exfoliated structures it is essential to modify the clay organically and thereby increase the affinity with the polyolefin matrix. The most common organic modification of clay is through quaternary ammonium salt and its derivatives, where the surfactant which is generally thermally weak undergoes decomposition, followed by Hoffman's elimination [8] which produces amines and volatile olefins, in relatively low range of processing temperatures $[9,10]$. The thermal stability of the organoclay is of great concern, as many polymer composites are melt-blended at high temperatures to yield polymer nanocomposite. Therefore, it is very necessary to pay attention to the thermal stability of cationic surfactants used in the organic modification of clay during the melting process, as this undesired degradation induces the failure of the clay layers to form exfoliated structures [11].

Many approaches have been established to overcome this problem, by modifying silicate layers with high thermally stable cationic surfactants such as phosphonium [12, 13], pyridinium [14], and imidazolium [15-18].

Recent reports revealed remarkable enhancements in polymer properties by the dispersion of various nanometer inorganic fillers $[19,20]$. Imidazolium based ionic liquids have been evaluated as clay modifiers and the major advantages are the enhancement of the thermal and flame retardant characteristics of the clays, in comparison to ammonium modified clay [21-23]. This is further motivated by the synthetic diversity of ionic liquids which offers large numbers of modified clays and composites with improved thermal stability and nonflammability [24,25]. In most of the successful cases a combination of intercalated and exfoliated morphologies has been achieved and the dispersion of nanoclays into the polymer matrix is yet a challenging problem. In this study, we compared the results of both alkyl ammonium and dialkylimidazolium modified clay on the thermal and rheological properties, and the results which were obtained using imidazole surfactants showed better thermal stability than that of the quaternary ammonium salts. Presence of long alkyl chains present in both the clay structures showed comparable rheological properties by allowing good exfoliation and the morphology of the nanocomposites was also assessed by the TEM analysis to obtain a degree of exfoliation.

\section{Experimental}

2.1. Materials. Polypropylene (PP-HF029, MFR $2.9 \mathrm{~g} / 10 \mathrm{~min}$ ) was supplied by Equate Petrochemicals, Kuwait. Hydrophilic montmorillonite clay (MMT) and alkyl ammonium modified montmorillonite (AMMT; Nanomer 1.31 PS) clay were procured from Aldrich Co. Ionic liquid and 1-hexadecyl-3methylimidazolium chloride $>98 \%$ were supplied by Iolitec.

2.2. Instruments. The FT-IR spectra were recorded on a JASCO FT/IR-6300. Microscopic techniques implemented are Scanning Electron Microscopy (SEM: JEOL Model
6300) and Transmission Electron Microscopy (TEM: JEOL Model JEM-3010). The thermal profile (differential scanning calorimetry) of the PP and PP nanocomposites was evaluated using DSC 60 A plus Shimadzu with a heating rate of $10 \mathrm{~K} / \mathrm{min}$ starting from 30 to $220^{\circ} \mathrm{C}$. Thermal degradations were performed in a TA thermogravimetric analyzer (Discovery TGA). Degradations were performed from $40^{\circ} \mathrm{C}$ up to $700^{\circ} \mathrm{C}$, in a nitrogen atmosphere and at a heating rate of $10^{\circ} \mathrm{C} / \mathrm{min}$. The thermogravimetric (TGA) and differential thermogravimetric (DTG) curves were plotted and the \% weight loss of samples at various temperatures was tabulated. The rheological analysis was performed on a Discovery Hybrid Rheometer (DHR-3), in the plate-plate geometry, using plates of $25 \mathrm{~mm}$ diameter and a sample thickness of $1 \mathrm{~mm}$. The measurements were conducted under a constant temperature, a variable frequency from 0.1 to $100 \mathrm{rad} / \mathrm{s}$, and an amplitude of deformation of $1 \%$ applied to obtain rheological parameters.

2.3. Preparation of IMMT. $20 \mathrm{~g}$ of MMT was added to $500 \mathrm{ml}$ deionized water and stirred vigorously using a magnetic stirrer for $5 \mathrm{~h}$. A solution of 1-hexadecyl-3-methylimidazolium chloride (2 CEC) in water/ethanol was added in portions. The reaction mixture was heated at $60^{\circ} \mathrm{C}$ for 8 hours followed by precipitation in methanol. The precipitate was repeatedly washed with ethanol and deionized water until no bromide ion could be detected by an $\mathrm{AgNO}_{3}$ solution and then dried in a vacuum oven at $80^{\circ} \mathrm{C}$ for $24 \mathrm{~h}$ and then ground to a fine powder.

2.4. Preparation of Polymer Nanocomposite. In the first stage, the clay powder and polypropylene (PP) pellets with different filler ratios $(1.25,2.5$, and 5) were carefully drymixed to ensure an adequate dispersion of the particles at the macroscale level. The mixture was then melt-mixed at $180-200^{\circ} \mathrm{C}$ in a lab scale twin screw extruder at a rotor speed of $100 \mathrm{rpm}$. The samples prepared from ammonium modified MMT (AMMT) were labelled as PP-AMMT-1.25, PPAMMT-2.5, and PP-AMMT-5.0 and corresponding samples from imidazolium modified MMT (IMMT) were labelled as PP-IMMT-1.25, PP-IMMT-2.5, and PP-IMMT-5.0.

\section{Results and Discussion}

3.1. FTIR Spectroscopy. Figure 1 shows the comparison spectra of various MMT. The common peaks corresponding to silicon-oxygen and aluminum-oxygen bonds are observed, respectively, at 1029 and $620 \mathrm{~cm}^{-1}$, the strong peaks at 520 and 460 assigned to magnesium-oxygen. A sharp peak at 1640 and broad peak at $3423 \mathrm{~cm}^{-1}$ corresponding to entrapped moisture, peaks at 3621-3633 corresponding to the hydroxyl groups were found in three clays. The bands corresponding to $\mathrm{N}$-bearing functional groups (1050 to $1600 \mathrm{~cm}^{-1}$ ) were observed in both AMMT and IMMT. In addition to the common peaks at 1460 an additional peak at 1572 was observed in IMMT, which is assigned to the quaternated imidazolium group [22]. 

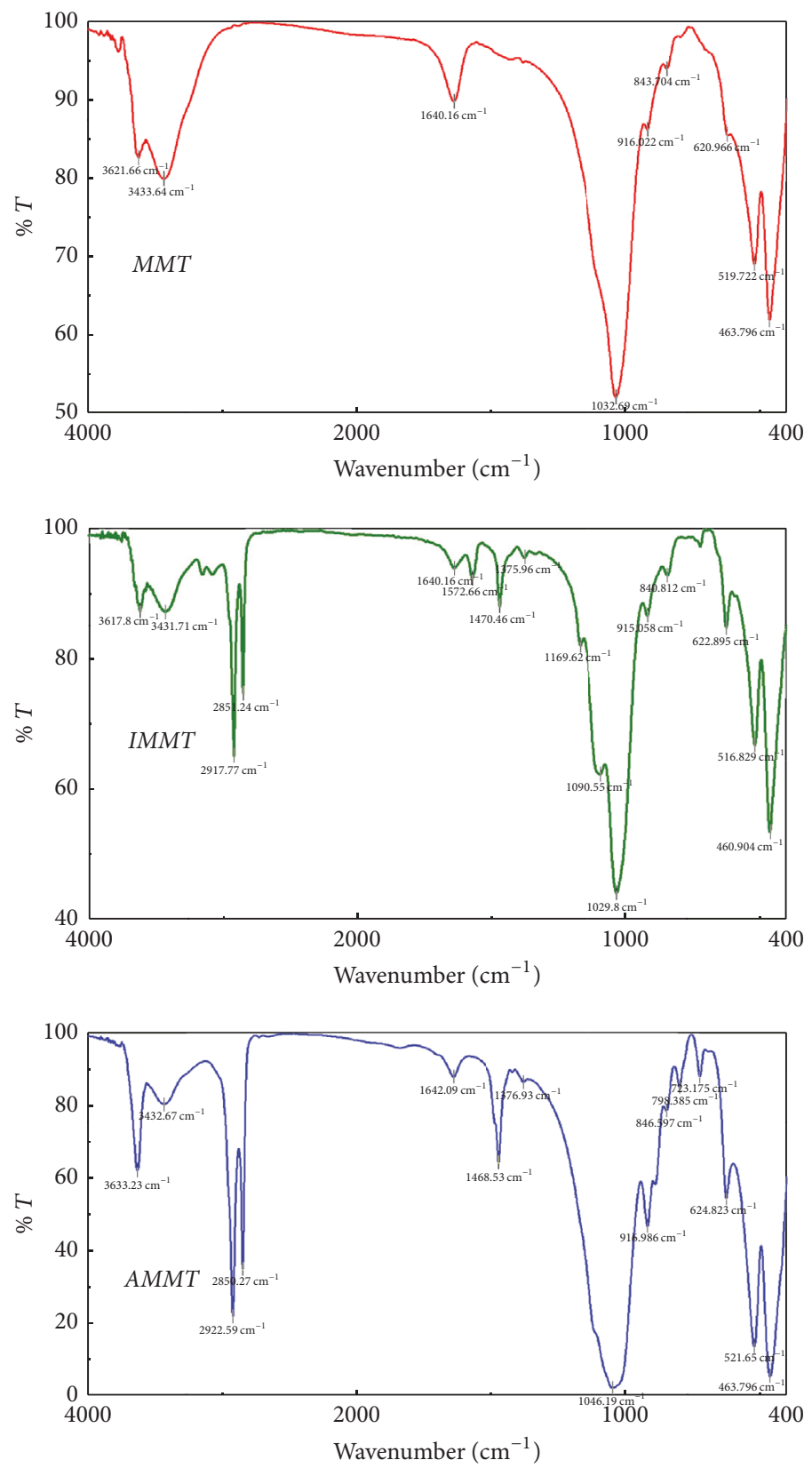

FIGURE 1: FTIR Spectra of MMT, IMMT, and AMMT.

3.2. Scanning Electron Microscopy (SEM). The Scanning Electron Microscopic technique was used to explore the surface morphologies of MMT, AMMT, and the prepared IMMT nanoclay samples. The surface morphologies of the MMT and AMMT nanopowders exhibit approximately the same surface morphologies seen with the exception of more aggregates in AMMT (Figure 2). The structure of the nanoclay powder modified by ionic liquid shows a massive thin layered structure with some large flakes and some interlayer spaces; this may be attributed to the chemical modification by large alkyl moieties in the clay galleries. All the samples show angular particles and aggregates with different sizes ranging from 1 to 30 microns.
3.3. Differential Scanning Calorimetry (DSC). The parameters from DSC analysis are summarized in Table 1, where the heating and cooling curves were recorded for the evaluation of the thermal properties (Figure 3). The melting temperature $\left(T_{m}\right)$ increased slightly up to $1.25 \mathrm{wt} . \%$ and decreased slightly at 2.5 and $5 \mathrm{wt} . \%$ in both PP-AMMT and PP-IMMT. The variation in the melting point indicated that the crystal structures of $\mathrm{PP}$ in nanocomposites were changed upon filler loading. The key concern in the design of polymer-clay nanocomposites is the monitoring of the distribution of clay nanoparticles on a polymer matrix. From the DSC results it was found that imidazolium modified clay (IMMT) exhibits low melting temperatures compared to the ammonium modified clay 


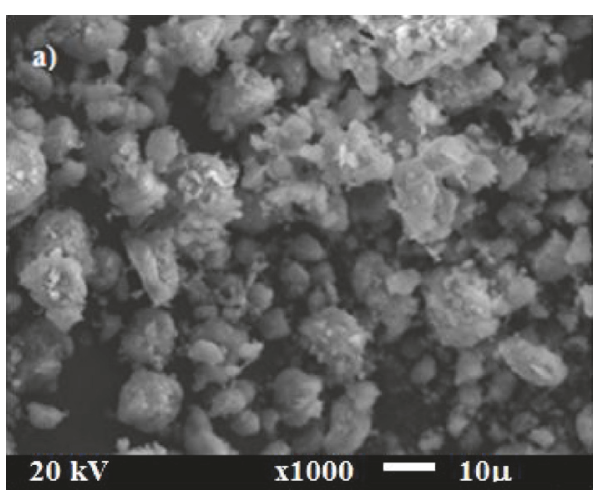

(a)

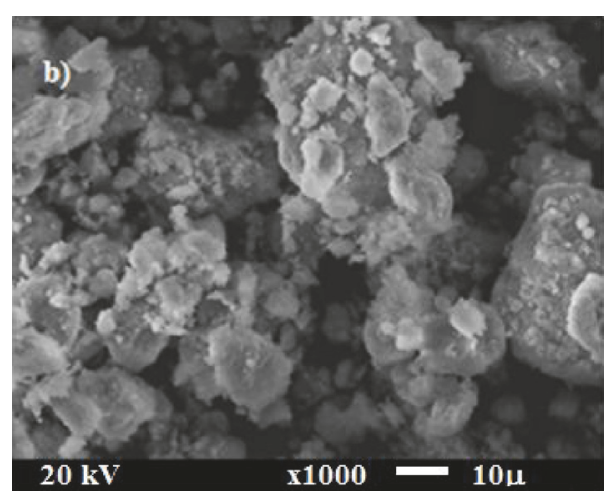

(b)

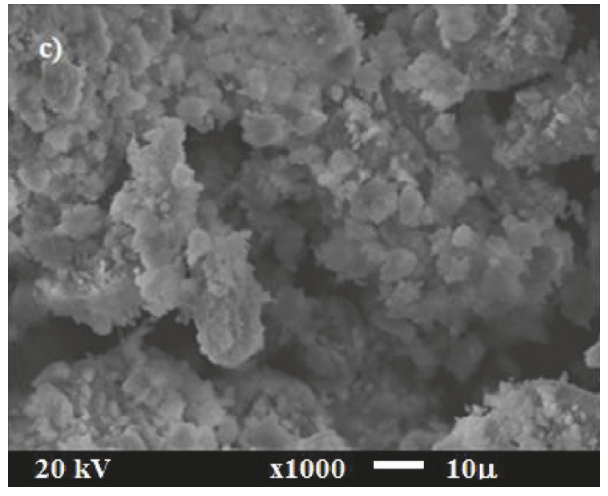

(c)

FIgURE 2: Scanning Electron Microscopic images of (a) MMT, (b) AMMT, and (c) IMMT.

TABLE 1: DSC and TGA characteristics of PP and its nanocomposites.

\begin{tabular}{lcccccc}
\hline Sample & $\begin{array}{c}T_{m} \\
\left({ }^{\circ} \mathrm{C}\right)\end{array}$ & $\begin{array}{c}\Delta H_{m} \\
(\mathrm{~J} / \mathrm{g})\end{array}$ & $\begin{array}{c}X_{c} \\
(\%)\end{array}$ & $\begin{array}{c}T_{c} \\
\left({ }^{\circ} \mathrm{C}\right)\end{array}$ & $\begin{array}{c}T_{\text {donset }} \\
\left({ }^{\circ} \mathrm{C}\right)\end{array}$ & $\begin{array}{c}T_{d \max } \\
\left({ }^{\circ} \mathrm{C}\right)\end{array}$ \\
\hline PP & 163.12 & 79.18 & 37.88 & 107.02 & 346.28 & 404.07 \\
PP-AMMT1.25 & 165.27 & 83.88 & 40.64 & 109.85 & 345.10 & 424.89 \\
PP-AMMT2.50 & 165.26 & 83.81 & 41.12 & 109.38 & 375.94 & 434.07 \\
PP-AMMT5.00 & 164.56 & 82.66 & 41.63 & 112.67 & 401.54 & 438.68 \\
PP-IMMT1.25 & 164.77 & 85.66 & 41.50 & 112.19 & 369.32 & 429.95 \\
PP-IMMT2.50 & 164.61 & 84.52 & 41.47 & 112.57 & 376.76 & 438.89 \\
PP-IMMT5.00 & 163.98 & 83.56 & 42.08 & 116.48 & 397.87 & 460.34 \\
\hline
\end{tabular}

(AMMT); this could be attributed to the effect of the long hydrophobic alkyl chain in the PP matrix. The crystallization temperature $\left(T_{c}\right)$ for both PP nanocomposites was higher than that of pure PP, and this can be explained by the effect where montmorillonite clay layers act as a nucleating agent for PP and increase of the crystallization rate. The crystallinity $\left(X_{c}, \%\right)$ calculation showed that the value increased $37 \%$ for unfilled PP and up to $42 \%$ for the filled PP and there was no visible correlation with the filler content. Moreover, it is vital to understand the interaction between the montmorillonite clay surfaces and the PP to prepare exfoliated clay-polymer nanocomposites.
3.4. Thermogravimetric Analysis (TGA). The effect of cationic modifications on the thermal behavior of PP clay nanocomposites was analyzed by thermogravimetric analysis TGA. The TGA parameters are stated in Table 1 and TGA traces are shown in Figures 4 and 5. Considering PP the thermal stability of the PP/clay nanocomposites was increased with increasing the clay content. Comparing PP-AMMT the onset degradation temperature $\left(T_{\text {onset }}\right)$ values of the PP-IMMT showed a substantial improvement. At higher filler loading (2.5 and $5 \mathrm{wt} \%$ ) the mass loss decomposition started almost at the same temperature for both PP-AMMT and PP-IMMT composites; such behavior is typical for a barrier effect due to the remaining silicate layers, acting as diffusion barriers for the oxygen [26]. The maximum degradation temperature $\left(T_{d \max }\right)$ also showed an improvement from $404(\mathrm{PP})$ to 460 (PP-IMMT-5) keeping a lower value of 438 (PP-AMMT-5). This is attributed to the effective exfoliation of IMMT into the PP matrix during the melt intercalation without any notable decomposition. Comparing the results obtained over the thermal degradation showed the clear effect of exfoliated silicate layers and how more pronounced they were during thermal degradation. These results and interpretations are in good correspondence with the results found for the thermal and thermal oxidative decomposition of PP silicate nanocomposites. While comparing the derivative curves, it was observed that both PP-AMMT and PP-IMMT decomposed via a single step degradation process similar to a 

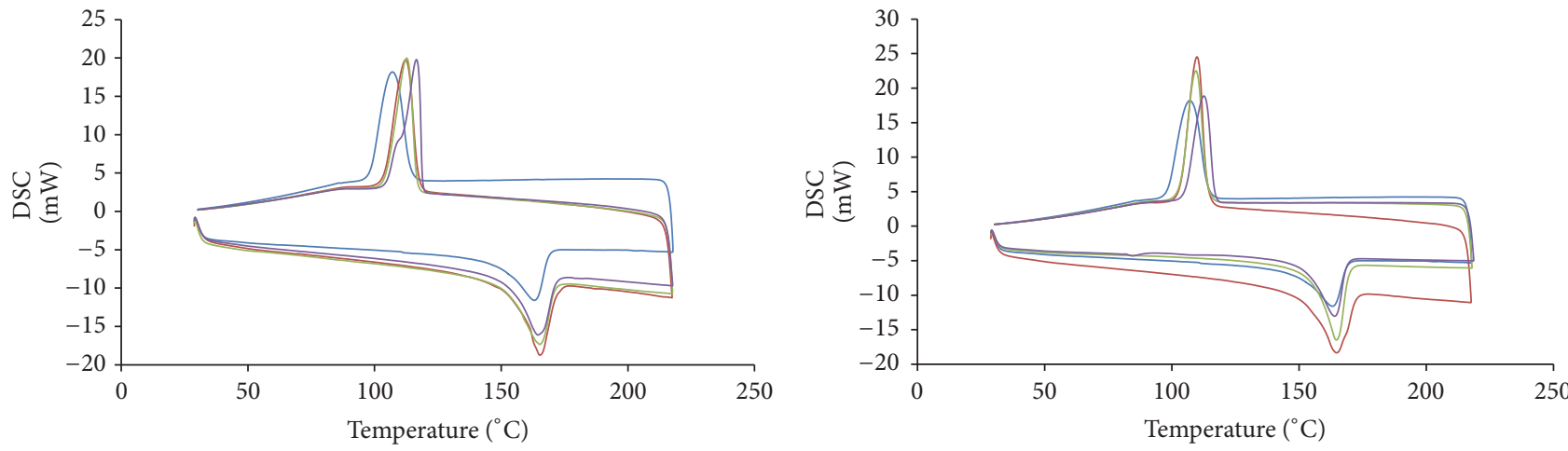
— PP
— PP-AMMT- 1.25
— PP-AMMT-2.50
- PP
- PP-IMMT1.25
— PP-IMMT2.50

FIGURE 3: Differential scanning calorimetric curves of PP, PP-AMMT, and PP-IMMT composites.
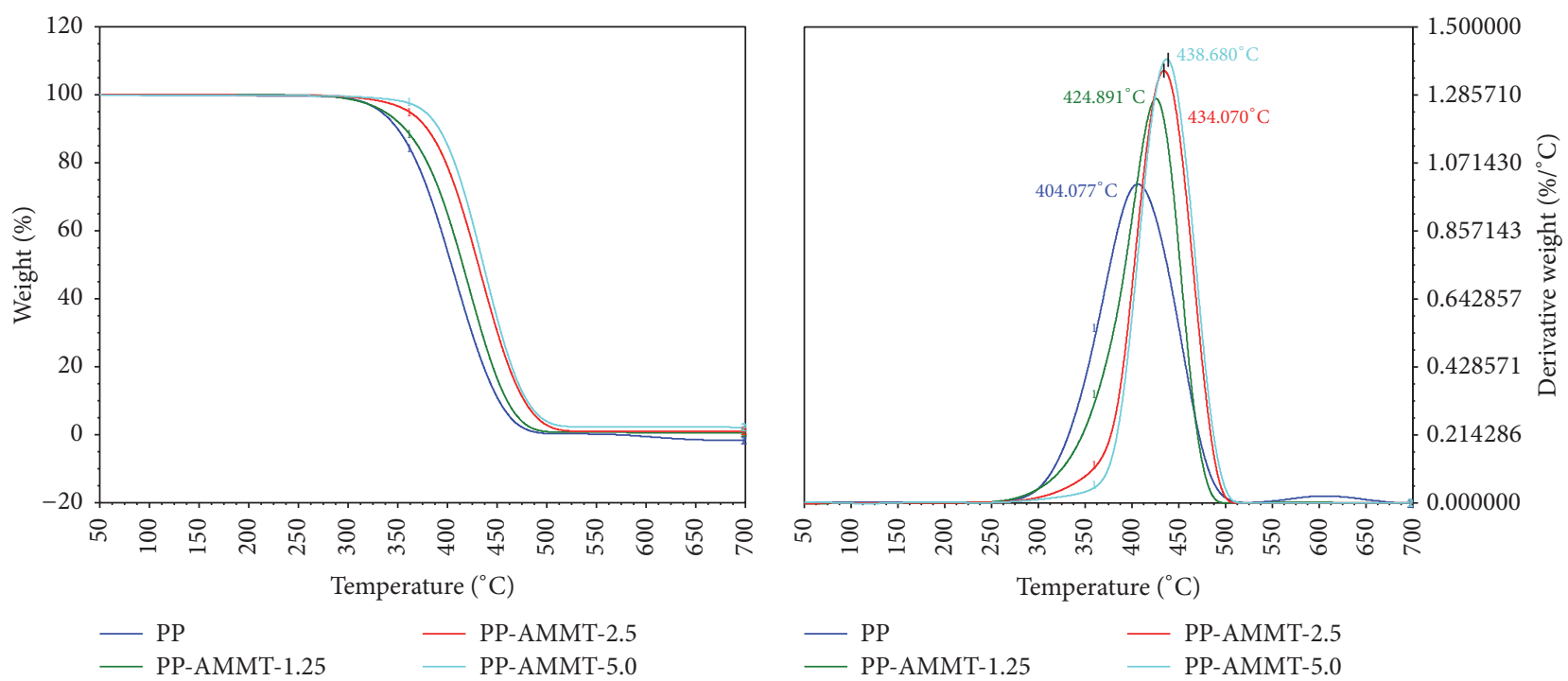

FIgURE 4: TGA trace and derivative curves of PP-AMMT composites.
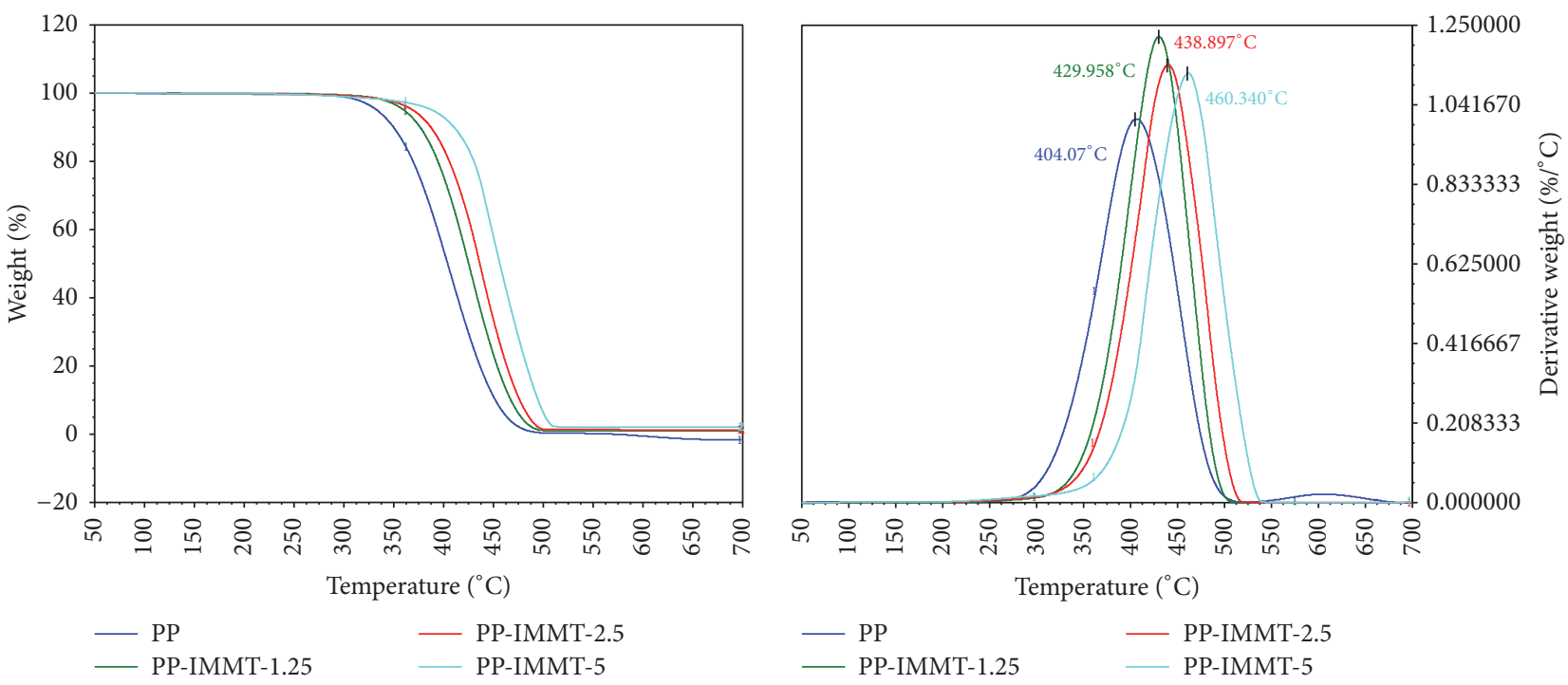

FIGURE 5: TGA trace and derivative curves of PP-IMMT composites. 


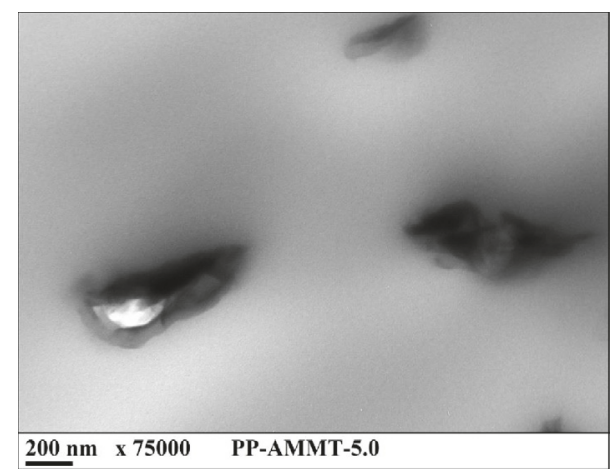

(a)

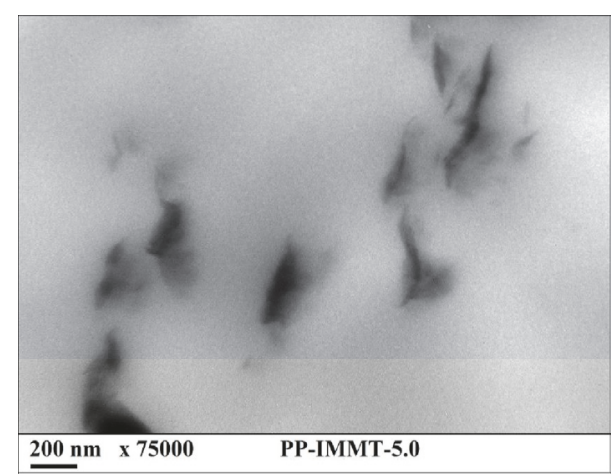

(b)

FIgURE 6: (a) TEM image of PP-AMMT composite. (b) TEM image of PP-IMMT composite.

TABLE 2: Rheological parameters of PP and its nanocomposites.

\begin{tabular}{|c|c|c|c|c|c|c|c|}
\hline \multirow[b]{2}{*}{ Sample } & \multirow{2}{*}{$\begin{array}{c}\text { Crossover } \\
\text { modulus } \\
\mathrm{MPa}\end{array}$} & \multirow{2}{*}{$\begin{array}{l}\text { Crossover } \\
\text { frequency } \\
(\mathrm{rad} / \mathrm{s})[\mathrm{Hz}]\end{array}$} & \multirow{2}{*}{$\begin{array}{l}\text { Relaxation time } \\
\text { (s) }\end{array}$} & \multicolumn{4}{|c|}{ Complex viscosity $(\mathrm{Pa} \cdot \mathrm{s})$} \\
\hline & & & & $\begin{array}{c}0.1 \\
(\mathrm{rad} / \mathrm{s})\end{array}$ & $\begin{array}{c}1 \\
(\mathrm{rad} / \mathrm{s})\end{array}$ & $\begin{array}{c}10 \\
(\mathrm{rad} / \mathrm{s})\end{array}$ & $\begin{array}{c}100 \\
(\mathrm{rad} / \mathrm{s})\end{array}$ \\
\hline $\mathrm{PP}$ & 26.76 & $15.86[2.52]$ & 0.39 & 11576 & 7130 & 2985 & 837 \\
\hline PP-AMMT1.25 & 26.25 & $14.16[2.25]$ & 0.44 & 12391 & 7546 & 3108 & 853 \\
\hline PP-AMMT2.50 & 26.70 & $14.60[2.30]$ & 0.43 & 12653 & 7726 & 3175 & 861 \\
\hline PP-AMMT5.00 & 27.29 & $14.41[2.29]$ & 0.44 & 12864 & 7797 & 3203 & 884 \\
\hline PP-IMMT1.25 & 26.18 & $15.34[2.44]$ & 0.41 & 11496 & 7124 & 2974 & 838 \\
\hline PP-IMMT2.50 & 26.48 & $14.78[2.35]$ & 0.42 & 11984 & 7298 & 3109 & 858 \\
\hline PP-IMMT5.00 & 26.91 & $14.64[2.33]$ & 0.43 & 11948 & 7376 & 3154 & 885 \\
\hline
\end{tabular}

pure PP sample. In all PP nanocomposite, clay particles acted as a shelter during the char formation, and as a result the second phase of degradation of the nanocomposite appears to occur at higher temperatures compared to that of pure polymers. However, when thermally stable, when imidazole was added to the nanocomposites, the initiation and maximum temperatures are shifted towards higher temperature; this effect is explained by the fine dispersion of the clay layers, which decreases the polymer permeability to both oxygen and the volatile decomposition products. The small volatiles which were raised during the thermal decomposition process cannot permeate but may avoid the clay layers; thus the addition of the clays reduces the release rate of the decomposed byproducts and hence enhances the thermal stability of the nanocomposites.

3.5. Transmission Electron Microscopy (TEM). Figure 6(a) shows an image of polypropylene melt intercalated with 5 wt.\% of ammonium based nanoclays; the image shows darker nanoscopic MMT aggregates distributed throughout the polypropylene matrix. This arrangement of clay platelets can be associated with that of an intercalated nanocomposite structure rather than the exfoliation. The main role of an organic modifier is to decrease the cohesion forces of clay stacks by changing the nature of MMT into organophilic and thereby allowing the polymer chain to intercalate into clay galleries. Figure 6(b) shows an image of a polypropylene structure infused with $5 \mathrm{wt}$.\% of imidazolium based nanoclay. In this image, mixed morphologies of exfoliated nanostructures have been observed, which show that, even at a higher filler loading, nanostructures are dispersed uniformly in the polymer matrix; another finding is that the morphologies of intercalated structures are not in close proximity to each other. This suggests the presence of a long alkyl chain in the clay surface well compatibilized in the polymer matrix and increasingly reinforced with less agglomerated clay sites.

3.6. Rheological Properties. The viscosity of the polymer melt usually plays an important role in the flow properties of the material; therefore rheological measurements are extensively used to study polymer melt. The parameters obtained will describe the fundamental behavior of polymer and its composites in processing (Table 2). The angular frequency dependence of shear storage modulus $\left(G^{\prime}\right)$ and shear loss modulus $\left(G^{\prime \prime}\right)$ complex viscosity $\left(\eta^{*}\right)$ at $180^{\circ} \mathrm{C}$ is plotted in Figures 7 and 8 for the virgin PP and its PP-AMMT and PP-IMMT composites, respectively. It is observed that both storage modulus and loss modulus increased with the increase in frequency and also with the increase in concentration of the filler content. It is also observed that the neat $\mathrm{PP}$ and its nanocomposite displayed viscous behavior at low frequencies $\left(G^{\prime \prime}>G^{\prime}\right)$ and an elastic behavior at high frequencies $\left(G^{\prime}>G^{\prime \prime}\right)$, with a particular frequency point at which a reverse of the behavior is achieved (crossover 


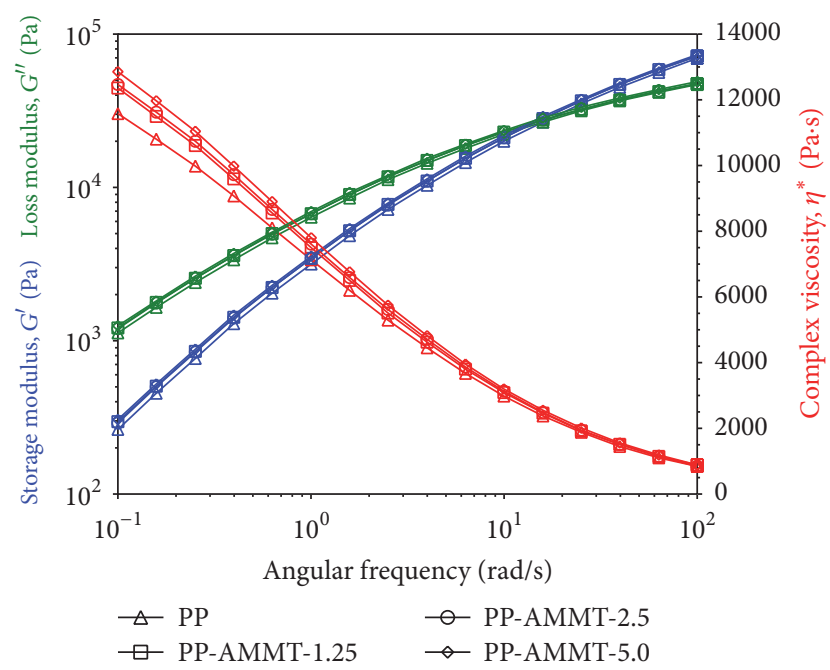

FIGURE 7: Rheological analysis of PP-AMMT composites.

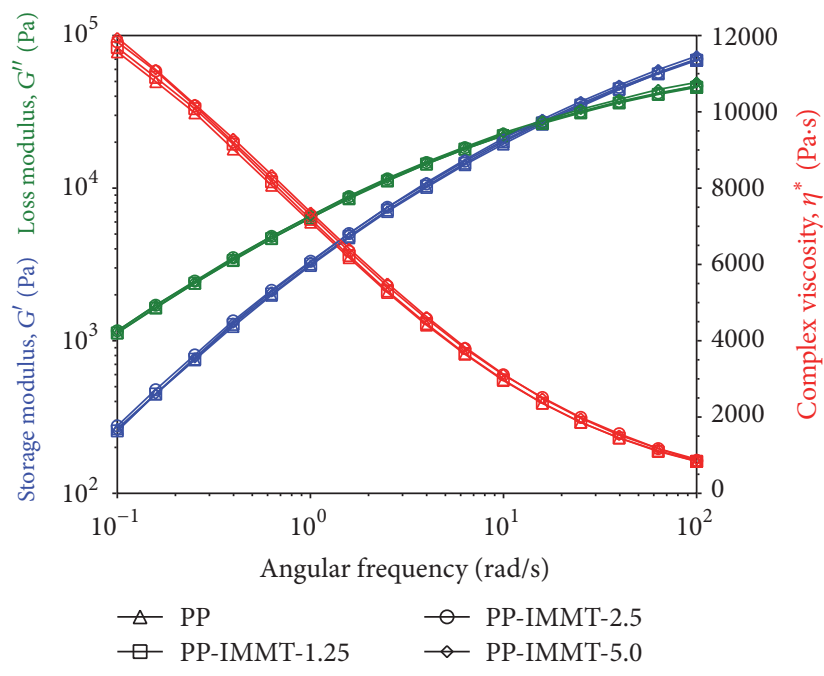

FIGURE 8: Rheological analysis of PP-IMMT composites.

frequency, $G^{\prime}=G$ ). The values of the crossover frequency and modulus values showed a similar viscous behavior of both PP-AMMT and PP-IMMT composites. It is important to note that presence of nanofillers in a polymer matrix induces a shift in the molecular chain mobility to exhibit pronounced elastic properties as well as delayed relaxation time as compared to the virgin polymer. This is attributed to the increasing of the polymer chain-nanofiller interactions; the molecular mobility is more hindered, and the relaxation time calculations showed that both PP-AMMT and PP-IMMT nanocomposites exhibited comparable values with delayed relaxation time upon nanofiller loading. It is very important to note that a better clay exfoliation should stimulate an increase in moduli and delayed relaxation times. The variation of the melt complex viscosity $\left(\eta^{*}\right)$ of PP-AMMT and PP-IMMT at different angular frequencies is shown in Table 2; a typical pseudoplastic behavior for the neat PP and its composites was observed. In the pseudoplastic behavior, with increase of shear rate, the polymer molten layers were sheared away resulting in reduced viscosity. It is evident from Figures 7 and 8 that the complex viscosity of the PP increases with the increase of the nanofiller fiber loading, which is associated with hindering of the mobility of chained segments. The values $\eta^{*}$ (Table 2) showed a reduction in complex viscosity for PP-IMMT nanocomposites compared to the PP-AMMT; therefore it is also relevant to note that the reduction in melt viscosity is an additional benefit for polymer composite processing.

\section{Conclusion}

Polypropylene based nanocomposites were prepared by using two different surfactants (ammonium and imidazolium) modified montmorillonite. The effect of structural features of both surfactants on thermal and rheological properties of the prepared composites was evaluated. The addition of modified clay accelerates the crystallization compared to pure PP and the value remains the same for both composites. The thermogravimetric analysis showed that the PP composites modified by imidazolium surfactants are more thermally stable than conventional alkylammonium PP composites; in addition, higher exfoliation promotes higher thermal stability than nanocomposites which is further confirmed by TEM analysis. It is found that organic modification on filler surfaces increases the viscosity of composites due to an increased filler-matrix interaction and the results were comparable. The melt viscosity measurements showed that imidazolium treated MMT filled PP exhibited a lower complex viscosity, and this is associated with the molecular motion due to the availability of greater free volume and weaker intermolecular interactions. The relaxation time measurements showed a comparable exfoliation degree for the composite structures.

\section{Conflicts of Interest}

The authors declare that they have no conflicts of interest.

\section{Acknowledgments}

This work was supported by the Kuwait Institute for Scientific Research (KISR) through the Research Project PC 019K.

\section{References}

[1] M. Alexandre and P. Dubois, "Polymer-layered silicate nanocomposites: preparation, properties and uses of a new class of materials," Materials Science and Engineering R: Reports, vol. 28, no. 1, pp. 1-63, 2000.

[2] E. P. Giannelis, "Polymer layered silicate nanocomposites," Advanced Materials, vol. 8, no. 1, pp. 29-35, 1996.

[3] Y. Kojima, A. Usuki, M. Kawasumi et al., "Mechanical properties of nylon 6-clay hybrid," Journal of Materials Research, vol. 8, no. 5, pp. 1185-1189, 1993.

[4] Y. Kojima, A. Usuki, M. Kawasumi, A. Okada, T. Kurauchi, and O. Kamigaito, "Synthesis of nylon 6-clay hybrid by montmorillonite intercalated with $\epsilon$-caprolactam," Journal of Polymer Science Part A: Polymer Chemistry, vol. 31, no. 4, pp. 983-986, 1993. 
[5] A. Chafidz, I. Ali, M. E. Ali Mohsin, R. Elleithy, and S. AlZahrani, "Nanoindentation and dynamic mechanical properties of PP/clay nanocomposites," Journal of Polymer Research, vol. 19, no. 7, article no. 9906, 2012.

[6] T. D. Fornes, P. J. Yoon, D. L. Hunter, H. Keskkula, and D. R. Paul, "Effect of organoclay structure on nylon 6 nanocomposite morphology and properties," Polymer, vol. 43, no. 22, pp. 59155933, 2002.

[7] H. Dalir, R. D. Farahani, V. Nhim, B. Samson, M. Lévesque, and D. Therriault, "Preparation of highly exfoliated polyester-clay nanocomposites: process-property correlations," Langmuir, vol. 28, no. 1, pp. 791-803, 2012.

[8] W. Xie, Z. Gao, K. Liu et al., "Thermal characterization of organically modified montmorillonite," Thermochimica Acta, vol. 367-368, pp. 339-350, 2001.

[9] M. Sepehr, L. A. Utracki, X. X. Zheng, and C. A. Wilkie, "Polystyrenes with macro-intercalated organoclay. Part II. Rheology and mechanical performance," Polymer, vol. 46, no. 25, pp. 11569-11581, 2005.

[10] R. Pfaendner, "Nanocomposites: industrial opportunity or challenge?” Polymer Degradation and Stability, vol. 95, no. 3, pp. 369-373, 2010.

[11] R. K. Shah and D. R. Paul, "Organoclay degradation in melt processed polyethylene nanocomposites," Polymer, vol. 47, no. 11, pp. 4075-4084, 2006.

[12] V. Mittal, "Modification of montmorillonites with thermally stable phosphonium cations and comparison with alkylammonium montmorillonites," Applied Clay Science, vol. 56, pp. 103109, 2012.

[13] M. Yousfi, J. Soulestin, B. Vergnes, M. F. Lacrampe, and P. Krawczak, "Morphology and mechanical properties of PET/PE blends compatibilized by nanoclays: effect of thermal stability of nanofiller organic modifier," Journal of Applied Polymer Science, vol. 128, no. 5, pp. 2766-2778, 2013.

[14] G. Chigwada, D. Wang, and C. A. Wilkie, "Polystyrene nanocomposites based on quinolinium and pyridinium surfactants," Polymer Degradation and Stability, vol. 91, no. 4, pp. 848-855, 2006.

[15] F. A. Bottino, E. Fabbri, I. L. Fragalà et al., "Polystyrene-clay nanocomposites prepared with polymerizable imidazolium surfactants," Macromolecular Rapid Communications, vol. 24, no. 18, pp. 1079-1084, 2003.

[16] J. U. Ha and M. Xanthos, "Functionalization of nanoclays with ionic liquids for polypropylene composites," Polymer Composites, vol. 30, no. 5, pp. 534-542, 2009.

[17] G. Cai, J. Feng, J. Zhu, and C. A. Wilkie, "Polystyrene- and poly (methyl methacrylate)-organoclay nanocomposites using a one-chain benzimidazolium surfactant," Polymer Degradation and Stability, vol. 99, no. 1, pp. 204-210, 2014.

[18] A. H. He, L. M. Wang, W. Yao, B. C. Huang, D. J. Wang, and C. C. Han, "Structural design of imidazolium and its application in PP/montmorillonite nanocomposites," Polymer Degradation and Stability, vol. 95, no. 4, pp. 651-655, 2010.

[19] G. S. Venkatesh, A. Deb, A. Karmarkar, and S. S. Chauhan, "Effect of nanoclay content and compatibilizer on viscoelastic properties of montmorillonite/polypropylene nanocomposites," Materials and Design, vol. 37, pp. 285-291, 2012.

[20] M. Entezam, H. A. Khonakdar, A. A. Yousefi, S. H. Jafari, U. Wagenknecht, and G. Heinrich, "On nanoclay localization in polypropylene/poly(ethylene terephthalate) blends: Correlation with thermal and mechanical properties," Materials and Design, vol. 45, pp. 110-117, 2013.
[21] J. W. Gilman, W. H. Awad, R. D. Davis et al., "Polymer/layered silicate nanocomposites from thermally stable trialkylimidazolium-treated montmorillonite," Chemistry of Materials, vol. 14, no. 9, pp. 3776-3785, 2002.

[22] E. E. Yalçinkaya, "In situ synthesis of poly(N-vinylimidazole)/ montmorillonite nanocomposites using intercalated monomer and thermal properties," Journal of Composite Materials, vol. 50, no. 4, pp. 533-542, 2016.

[23] N. H. Kim, S. V. Malhotra, and M. Xanthos, "Modification of cationic nanoclays with ionic liquids," Microporous and Mesoporous Materials, vol. 96, no. 1-3, pp. 29-35, 2006.

[24] X. Han and D. W. Armstrong, "Using geminal dicationic ionic liquids as solvents for high-temperature organic reactions," Organic Letters, vol. 7, no. 19, pp. 4205-4208, 2005.

[25] W.-F. Cui, X.-H. Gao, and Y.-P. Wang, "Modification of vermiculite with ionic liquids," Asian Journal of Chemistry, vol. 22, no. 2, pp. 911-920, 2010.

[26] A. Leszczyńska, J. Njuguna, K. Pielichowski, and J. R. Banerjee, "Polymer/montmorillonite nanocomposites with improved thermal properties. Part I. Factors influencing thermal stability and mechanisms of thermal stability improvement," Thermochimica Acta, vol. 453, no. 2, pp. 75-96, 2007. 

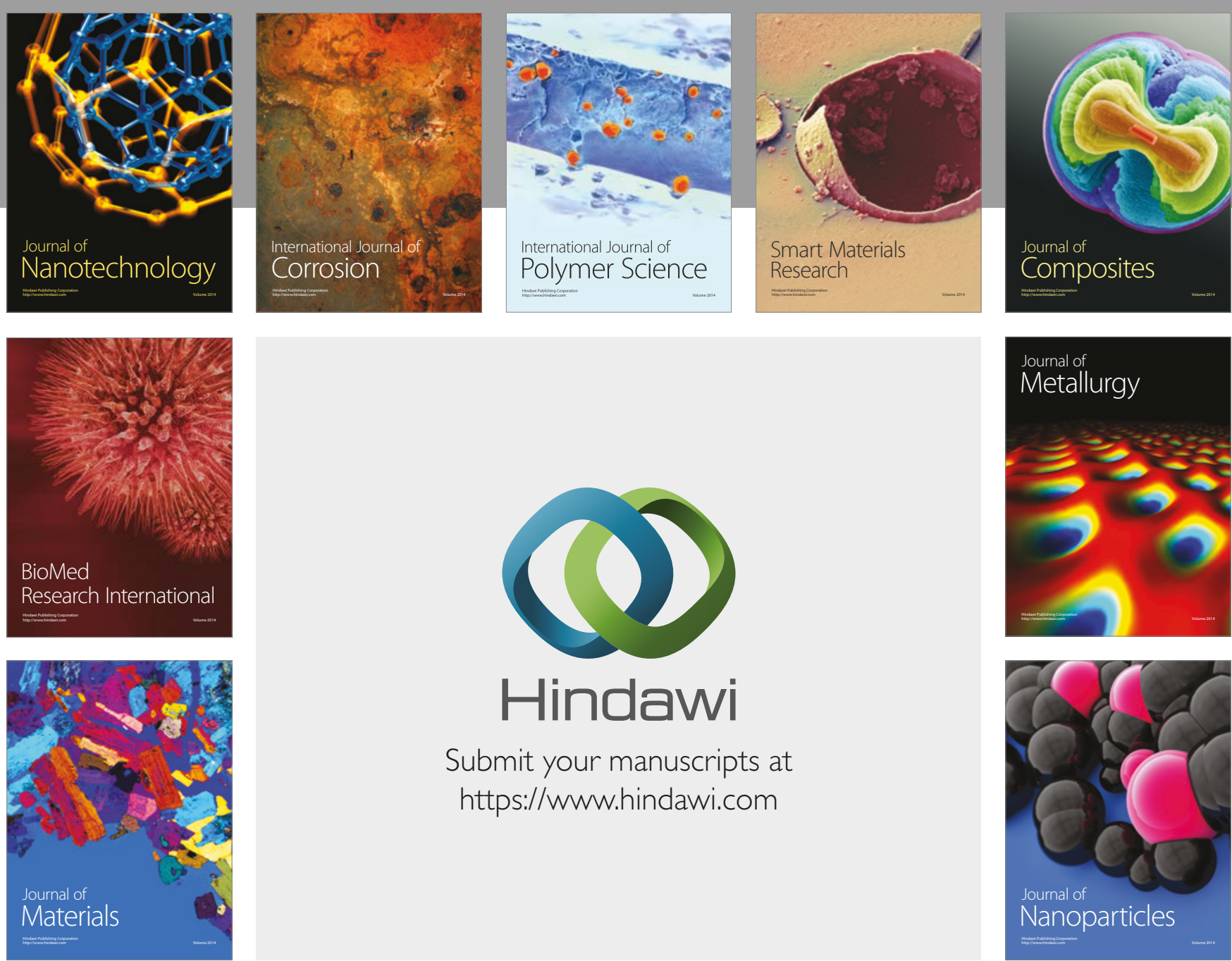

\section{Hindawi}

Submit your manuscripts at

https://www.hindawi.com
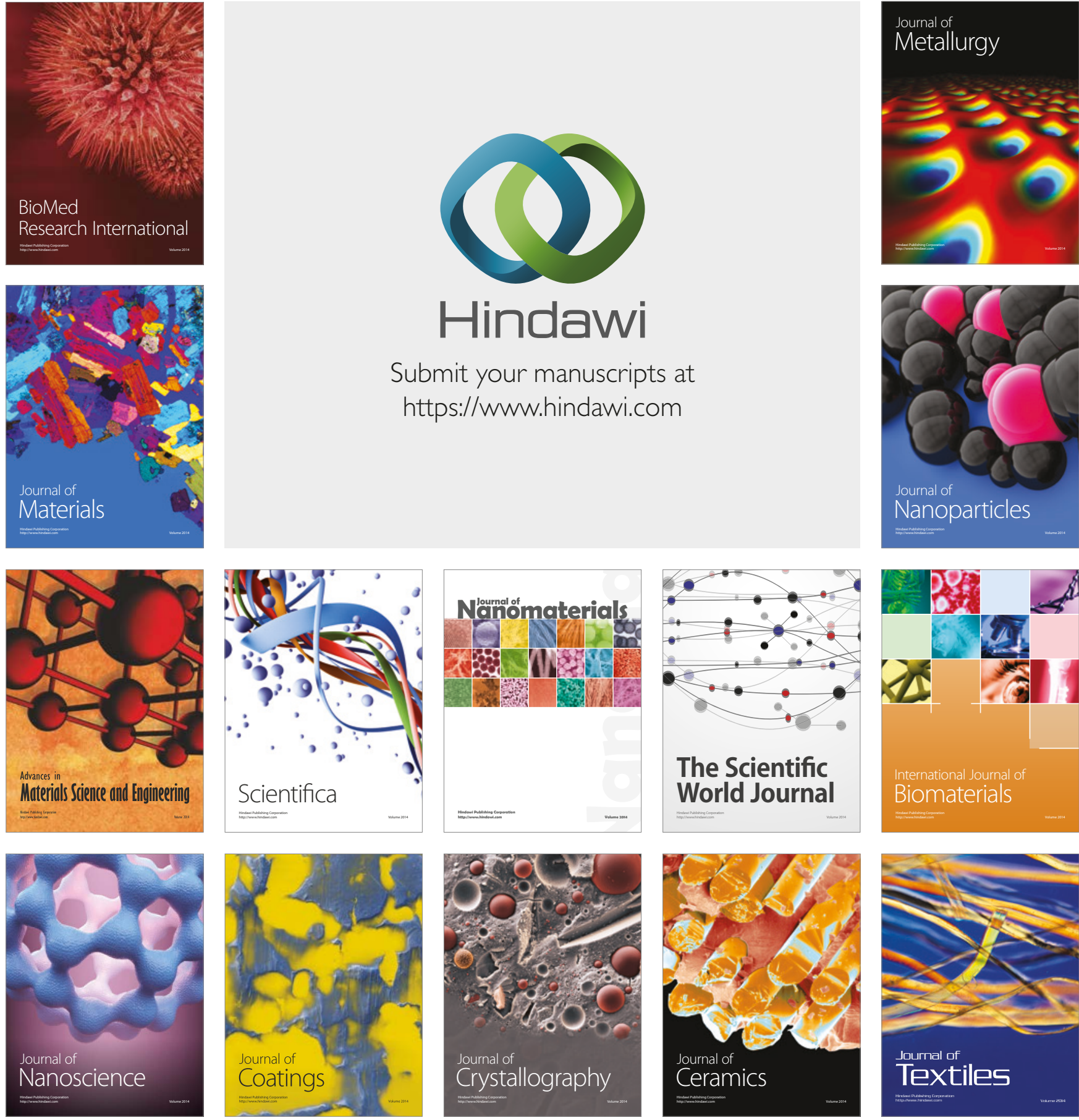

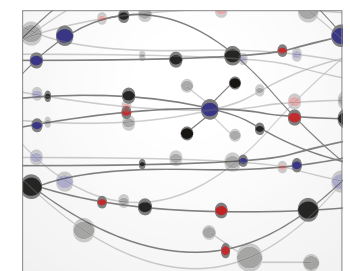

The Scientific World Journal
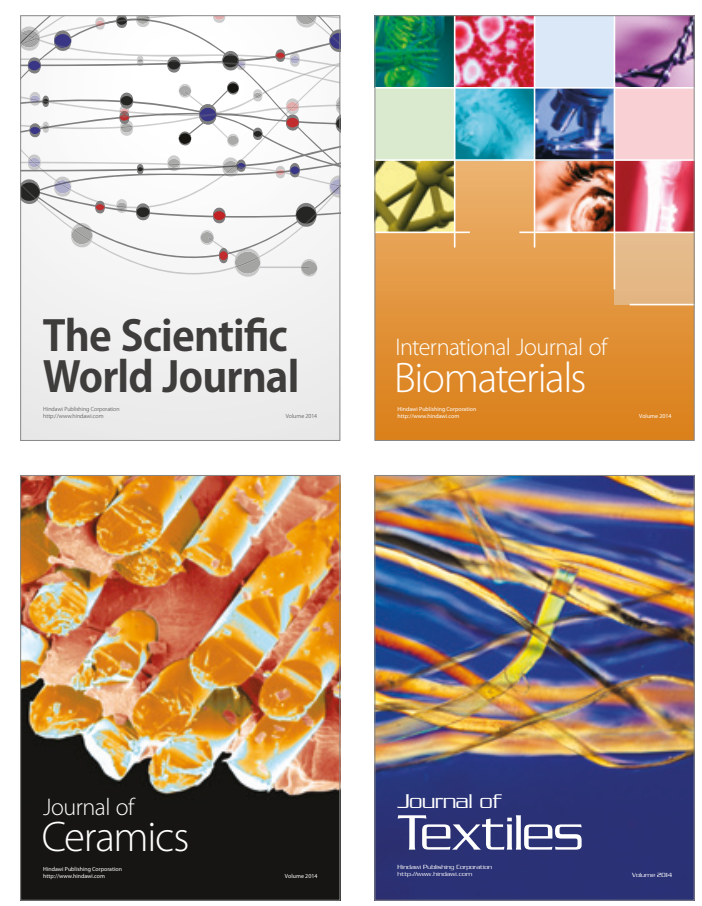